\title{
18
}

\section{Conversation across cultures}

Mark Dingemanse and Simeon Floyd

For ethnography, there is no richer ore than everyday conversation.

(Moerman 1988: 18)

\subsection{Introduction}

Informal conversation is a practice found among speakers of every language in every culture on Earth. Or is it? Is conversation just one of many culturally variable speech genres, or is it the informal baseline on which all other genres are built? Can the same type of basic turn-taking system be observed in all languages, or does it vary analogously to the ways that grammatical systems do? Are conversational actions such as "asking questions" or "giving directives" present in every culture, or are these culture-specific categories based on English, meaning that other cultures have their own distinct categories? These questions are central not only to understanding language usage, but also to conceptualizing human sociality more generally. Larger social realities are built up from thousands and thousands of small-scale interactions, so a social scientist's need to understand these tiny moments is a bit like a physicist's need to understand subatomic particles. Given its fundamental nature, it is surprising that conversational interaction has, with a few notable exceptions, mainly been treated peripherally to other domains in linguistic anthropology. Reasons for this are complex, involving both disciplinary histories as well as changing technological constraints on the collection of corpora of audio/video data in many different linguistic and cultural contexts. This history is discussed in more detail below, but initially it is worth revisiting the origins of the modern-day study of talk in interaction with respect to our present questions about conversational practices across cultures. 
In the late 1960s at UCLA the ethnographer Michael Moerman witnessed first-hand and participated in the birth of the new subdiscipline of Conversation Analysis. While the early findings of Sacks and his colleagues were exclusively based on English-language recordings, Moerman had field recordings from his work in Tai/Lue-speaking communities of Thailand, and he was curious to revisit them in light of recent observations about English. He discovered that some conversational practices were strikingly similar cross-linguistically, much more so than cultural relativists might predict. At the same time, he noted that not everything in the data was cross-culturally comparable, and that the knowledge that he had accumulated through long-term ethnographic fieldwork was sometimes crucial in understanding specific interactions. These experiences led Moerman to pioneer an approach that took "ethnography with its concern for context, meaning, history" and connected it with the "techniques that conversation analysis offers for locating culture in situ" (Moerman 1988: xi). This innovative proposal arrived to much interest, as evidenced in many reviews and in a special issue of Research on Language and Social Interaction with contributors from several disciplines including anthropology and conversation analysis (Hopper 1990; Heritage 1990; Mandelbaum 1990; Streeck 1990; Pomerantz 1990; Beach 1990; Moerman 1990; and other articles in the same issue). However, it was not followed by a boom in studies of conversational interaction in the languages of the world. Conversation analysis stuck mainly to English, in part due to concerns that ethnographic methods would introduce data from beyond specific transcribed interactions that could not be studied in the same way (Schegloff 1992; Sanders 1999; McHoul et al. 2008). Descriptive linguistics continued to make great advances in documenting the world's diversity of linguistic structures, but has had less to say about language use in interaction (though see Ochs et al. 1996). Linguistic anthropology has always privileged the speech situation (Hymes 1974), but many of its advances have been centered on formalized language, where cultural variation tends to be especially salient, and its most recent paradigm has focused more on macro-political concerns than micro-interactional ones (Duranti 2003).

The cross-cultural comparative study of conversation has commenced only recently, but new advances suggest that we may be poised for a period of new emphasis and discoveries in this area. In this chapter we trace the origins of this emerging field and sketch some of its preliminary findings, and we assemble a set of tools and best practices from across different disciplines. We aim to aid students of language and culture in pursuing a new paradigm of ethnographic, cross-cultural, field-based studies of social interaction. The central puzzle of this chapter is: how is conversation structured, to what extent do its structures vary culturally and across various languages - and which interdisciplinary methods can contribute to resolving these questions? 


\subsubsection{Defining "conversation" and "culture"}

Conversation is sometimes seen as a speech genre, to be contrasted with other genres such as political oratory or narrative. Here, however, we use it as a technical term to foreground a focus not on genre or text type but on the technical details of talk-in-interaction concerning a set of generic organizational problems that have to be dealt with in any occasion of social interaction: how to organize turn-taking between participants; how to work out the relations between successive turns at talk; how to deal with interactional trouble; how to compose turns out of smaller elements; and how to structure an occasion of interaction (Schegloff 2006).

Many specialized types or genres of interaction feature predetermined solutions to some or all of these problems - for instance, the explicit turn allocation procedures in court hearings, the restrictions on answers in a game of Twenty Questions, the duration of a prison visit, or the rules for interaction with spirits in a divination session. However, no society is known where social interaction happens exclusively in such predetermined ways. Instead, people across the globe dedicate substantial amounts of time to more informal spates of social interaction. It is here that we may expect to find generic, self-organizing (as opposed to specific, pre-determined) solutions to the organizational problems of social interaction. If our goal is to compare the technical organization of talk, here we may find a promising baseline for cross-cultural comparison, since the more specific formalized restrictions there are on an interaction, the less comparable it becomes. With this goal in mind, we define conversation as maximally informal social interaction. While not forgetting that even the most informal conversations can be studied with respect to formalized practices reflecting, for example, social asymmetries between interlocutors, the sense in which we use the term "conversation" foregrounds close attention to the organizational practices of conversational sequences. This perspective takes seriously the fact that conversation constitutes one of the most common - perhaps the most common - forms of language use, and is also an important medium for language acquisition and socialization (Schieffelin and Ochs 1986; Goodwin and Heritage 1990; cf. this volume, Chapters 8 and 16).

If we are interested in comparing structures of conversation crossculturally, then we also must clarify what constitutes cross-cultural comparison. It was once common in anthropology to speak of "cultures" in the plural, but critiques of the culture concept (e.g., Abu-Lughod 1991) have problematized any simple way of talking about discrete, bounded cultural groups. Our use of the term culture is informed by these critiques, but instead of avoiding the word we attempt to use it in a more sensitive way. ${ }^{1}$ The idea of cultural difference we invoke here should be understood as complex and partial, and when we advocate comparing video corpora from different cultures we really mean comparing samples 
recorded in particular communities at particular times, assuming that this data is representative at some tractable level of a larger social group. But the main reason we advocate cross-cultural studies of conversational interaction is straightforward: besides a few notable exceptions, historically the study of conversation has been dominated by work on English, and while findings on English are usually not explicitly framed as representative of all cultures, this is sometimes the implication. While this ethnocentrism is more pragmatic than dogmatic, it is still problematic, and we are hesitant to accept any of these findings as more than particularities of English speakers until similar topics have been studied crossculturally. $^{2}$

\subsubsection{A piece of data}

Informal talk can be studied across different human societies: it can be inspected for how it helps construct distinct linguistic and cultural worlds and for how it may itself be subject to linguistic and cultural inflection. Any stretch of conversation shows that participants rely on a combination of interactional, linguistic, and cultural competencies to bring off even seemingly simple sequences (Keating and Egbert 2004). Consider the following extract of everyday conversation in Siwu, a Niger-Congo language spoken in Ghana. Kofi, Aku, and some others are chatting while shelling corn by hand. Kofi launches a story about something he saw the other day.

Extract 1. Siwu (Ghana) [Neighbours_1958690] $]^{3,4}$

1 Kofi Éi! (0.7) Ǹgəngbe to o-nyagẽ k̇̀makades. INTJ REL.CM-this PROG SCR-contort yesterday 3SG.TP 'Hey! (0.7) This one, she was behaving strangely yesterday.'

2 Aku ìna $s$ de? who 3 SG be?

'Who's that?'

3 Kofi Jbuafo Yawa:

PSN PSN

'Obuafo Yawa:'

4 Aku so be? ((shifts gaze towards Kofi))

QT what 'What?'

5 Kofi ((3.7s: shakes upper torso and head from side to side, eyes closed; see Figure 18.1))

$6 \quad$ kà̀. (0.2) kpaìtiri. (0.3) [Adom i]yo. ING-SR leave forum PSN house 'She. (0.2) went from the forum. (0.3) to Adom's House.'

$7 \quad$ Aku

[kùyo- ] kùy j-kpese ku-ba:? spirit spirit SR-return it-come 'The spirit - the spirit came back?' 
8 Kofi Àdom iyo-Àdom sre iyo kàmá-ba ma-tere-gu ũ̀ ma-kèlè-gu kòmakade. PSN house PSN wife house IN G 3 P L-come 3PL-run-COM her 3PL-go-COM yesterday

'To Adom's House - Adom's wife's house, she was dragged yesterday.'

9 Aku [Yes. ]

'Yes.'

10 Beatrice [’̀-š o-]kpa koko:?

3SG-H A B 3 S G-possess before

'She's been possessed before?'

11 Aku igogò ama.

year last

'Last year.'

Kofi starts a telling with an attention-calling hey! and a story preface. After clarifying the identity of the protagonist, Aku asks what happened (line 4). Kofi responds with a communicative move that contains no speech: he closes his eyes and shakes his upper torso and head from side to side (line 5, and see Figure 18.1). All present turn towards Kofi to look at this demonstration. In overlap with a verbal increment by Kofi (line 6), Aku presents a candidate understanding of his non-verbal enactment: "The spirit - the spirit came back?" (line 7). Kofi confirms this by continuing his description: she was being "dragged around" by the spirit yesterday. In overlap with a news receipt by Aku, Beatrice asks whether this person has been possessed before (line 10), which Aku confirms.

Various structural features of this sequence are readily recognizable as having equivalents in many languages. Examples are the story preface in line 1 with its typical "promise of interestingness" (Sacks 1992); the otherinitiated repair sequence in lines 2-4 (Schegloff et al. 1977); the brief violation of the turn-taking norms in line $7 \mathrm{a}$ in the form of an overlap occurring at a place where speaker transition could have occurred (Sacks

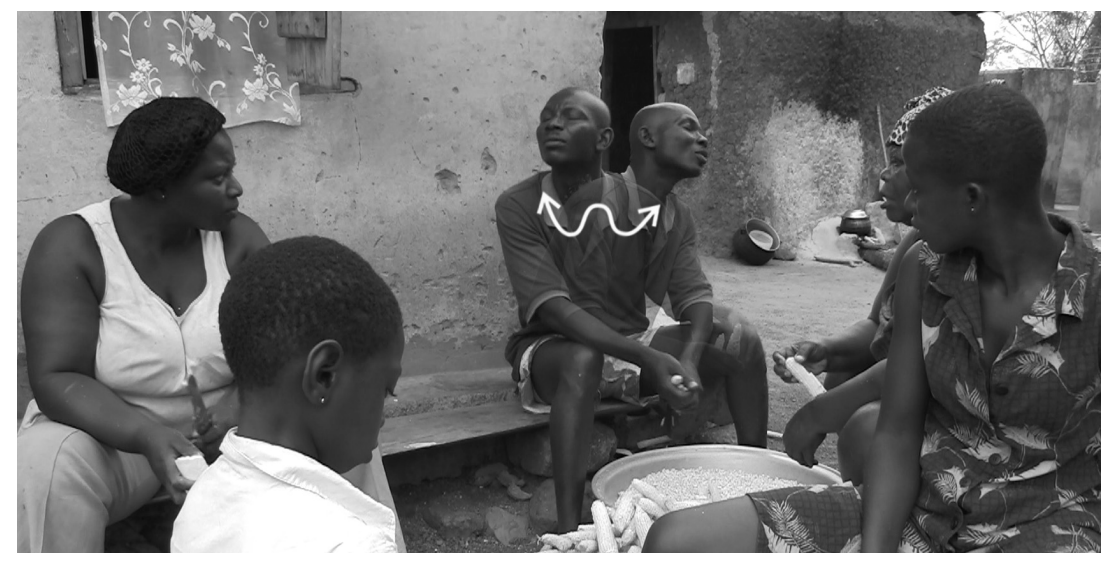

Figure 18.1 Depiction of Kofi's movements in line 5 from Extract 1 (two stills superimposed) 
et al. 1974); the quick resolution of this overlap by means of a cut-off and restart in the same line (Schegloff 2000); the candidate understanding in line $7 \mathrm{~b}$, which serves the progressivity of the sequence by advancing the telling (Antaki 2012); the self-repair by means of a cut-off in line 8 , which recycles some just-said material and inserts some new material (Schegloff 2013); the use of a question and directional gaze in line 4 to select a next speaker (Lerner 2003); the way questions and responses form adjacency pairs in lines 2-3, 4-5, and 10-11 (Schegloff 1968; Enfield et al. 2010); and the structural organization of the larger sequence itself, with basic adjacency pairs like the question-answer sequences, but also the more specific pre-telling and its go-ahead response in lines 1 and 4, and the insert sequence of other-initiated repair in lines 2-3 (Schegloff 2007).

At the same time, these routinely produced conversational structures cannot be understood without reference to cultural knowledge. When Kofi starts his story in line 1, his noticing of someone's strange behavior achieves its relevance in relation to the others' understanding of what their world is normally like (Moerman 1988). The way the underspecified person reference is spelled out in line 3 presupposes knowledge of the available formats for person reference and their relative ordering in this society and for these participants (Sidnell 2005; Levinson 2007). Aku's interpretation of Kofi's wordless depiction in line 5 (Figure 18.1), and her treatment of it as a satisfactory answer to her question, crucially depends on knowing local cultural models of spirit possession (Field 1969; Cohen 2008). The places referred to by Kofi in lines 6 and 8 gain their significance from the fact that they are important landmarks in the village: the forum is the main public space, accounting for where and why Kofi saw the reported events, and Adom's House is the former residence of a wellknown clan elder. The self-repair that corrects "Adom's House" to “Adom's Wife's House” in line 8 reflects the history of Adom's high-profile conversion to Christianity and divorce and move away from his influential priestess wife, who stayed in their old residence - highlighting the deep connections that some places can have to traditional ritual and religion (Smith 1992). In line 10, Beatrice's question whether this has happened to this person before draws attention to the out-of-the-ordinary nature of possession and the notion that such things do not happen to just everyone (Stoller 1989). And so on; these readings can be multiplied for all kinds of background understandings that come into play and help the interaction come off smoothly.

This extract therefore brings to the surface many of the issues that render conversation such a rich source for ethnography and ethnography an indispensable tool for understanding conversation across cultures. It is unclear how conversation-analytic methods would be able to entirely make sense of what is going on here without access to additional ethnographic information. What combination of deep cultural common ground, 
presupposed understandings, and interactional norms allow the participants in this interaction to bring off this seemingly simple sequence of communicative moves? How can the kind of ethnographic information generated by long-term participation in a society be used to complement the information that can be discovered in the transcribed instance itself, while still staying true to the intrinsic and emergent nature of the orderliness of a particular instance?

The only way to face the challenges posed by these questions is for researchers to combine anthropology's methods of long-term research participating in a community with recording and transcribing sequential data from the same community. ${ }^{5}$ The importance of bringing ethnographic understandings to the table has not been widely appreciated in conversation analysis. One reason for this is that the majority of studies have focused on English and a few other major languages in urban settings with official status and writing systems (German, Finnish, Japanese, etc.), and have been carried out by native members of these societies (Schegloff 2005) who are able to rely on their own assumptions and those of their readers - for providing cultural context (Moerman 1996). ${ }^{6}$ In contrast to this small subset of well-studied languages, the greater part of the world's linguistic diversity is represented by smallscale, unwritten languages, often spoken in remote places (Nettle 1998), If languages like these are excluded from comparison, the possibilities of documenting diversity or making cross-cultural generalizations are seriously compromised. Such languages have historically been the focus of cross-linguistic grammatical typology, but rarely have they been compared in terms of interactive structures and practices in a complementary typology of language usage. Anthropological linguistic fieldworkers have an important role to play in the development of such a paradigm because their ethnographic methods are a key component that can help make recordings of specific instances in possibly unfamiliar societies penetrable to analysis in the first place.

\subsection{Tools and their affordances}

While trusted field-notes-based methods continue to be central to linguistic and anthropological field research, fieldworkers have also been quick to adopt new recording technologies, and replacing earlier unwieldy and poor-quality options with high-quality portable video recording has opened up a world of millisecond timings and multimodal practices that were difficult to approach through earlier methods. There is no special insight inherent in the technology itself, but the ability to catch fleeting moments for repeated close observation has introduced new kinds of data and new questions to the field, and the emergence of new areas of interaction research is intertwined with these technological 
developments. Today a researcher interested in conversation who refuses to use video might be seen as similar to an astronomer turning down a telescope. This section traces a few historical developments leading up to the present paradigm in which the video camera has become a standard fieldwork tool.

\subsubsection{Early video analysis}

As far back as the early twentieth century Franz Boas was using film and wax cylinders to document elements of native North American culture (Ruby 1980), ${ }^{7}$ but in a "salvage anthropology" framework focused more on formalized events than mundane interactions. Boas's contemporary and gesture studies pioneer David Efron supplemented his notebook sketches of body behavior by experimenting with slow-motion film (Efron 1941: 66-7), now a basic method in multimodal analysis. Margaret Mead and Gregory Bateson also used film in the 1940s and 1950s for cross-cultural study of bodily practices, as seen in their film Bathing Babies in Three Cultures (Bateson and Mead 1951; see Figure 18.2), which compared the behavior of New Guinean, Balinese, and American parents by looking at similar mundane daily moments in each context (Jacknis 1988).

There were other early applications of film beyond the American anthropological tradition, but these ethnographically minded precursors are particularly relevant for current linguistic anthropological approaches to bodily behavior because they emphasized its cultural basis rather than its psychological or physiological aspects. In later decades the relationship between culture and body behavior was approached in a number of ways, including Edward Hall's program of "proxemics," which looked at cultural differences in the management of physical space (Hall 1963), and Ray Birdwhistell's approach to motor behavior, called "kinesics" (Birdwhistell 1952; cf. Davis 2001), which was applied cross-culturally in studies like that shown in the film Microcultural Incidents in Ten Zoos (1969), contrasting the bodily behavior during visits to the zoo of families from ten different cultural backgrounds. Other trajectories of research have had great influence on current uses of video as a part of field methodology, notably in early work of Adam Kendon, who used film to study greeting sequences at a North American social event (Kendon 1990), and in the paradigm of human ethology as seen in the work of Eibl-Eibesfeldt (1979; 1989), in which observational methods are similar to those applied to nonhuman animals. Spurred on by the increasing accessibility of video equipment, modern gesture and multimodality studies have developed in dozens of different directions that we cannot review here, but two important questions for researchers of conversation across cultures arise out of this history of close analysis of video data: (1) In what ways is cultural specificity and variation manifest in bodily behavior? and (2) What are the implications of the cultural elements of bodily behavior for the paradigm 


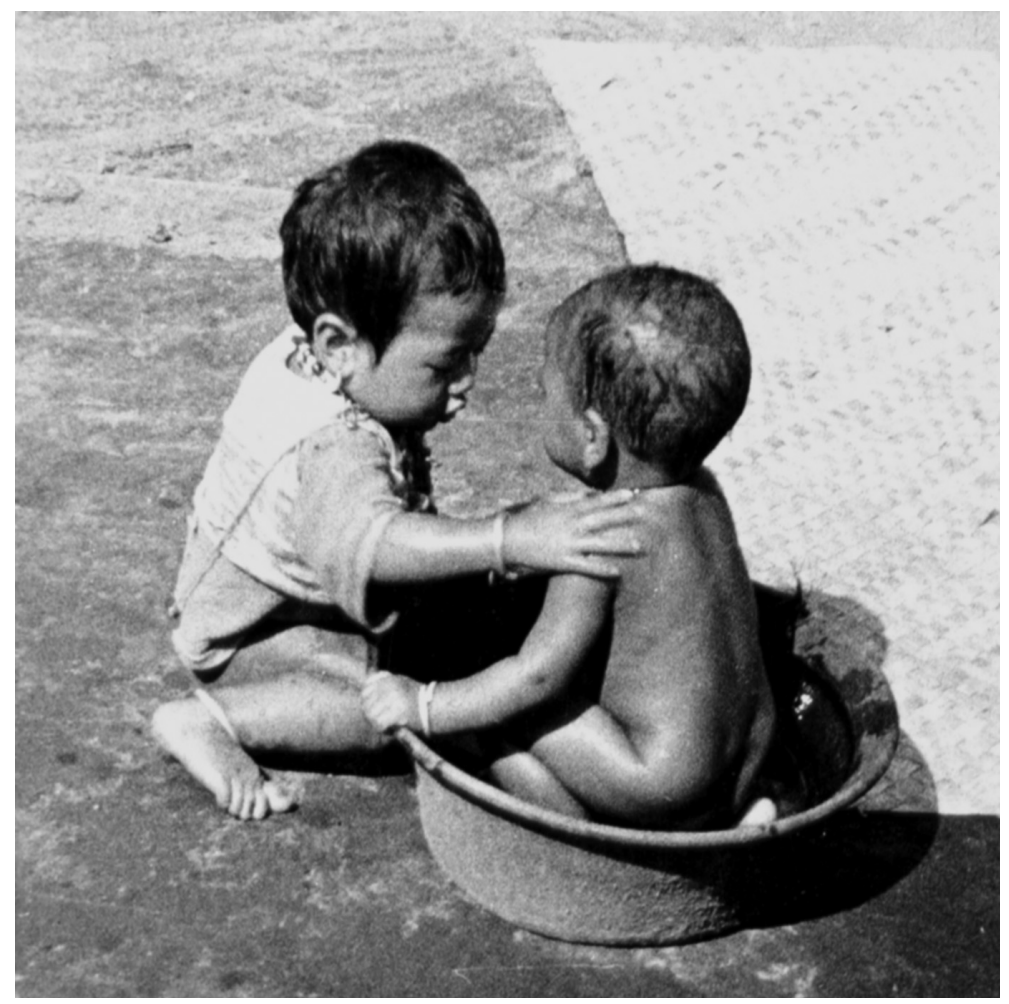

Figure 18.2 Household settings in which Mead and Bateson used film to compare body behavior across cultures; they compared bathing practices to families in Bali (pictured here) to those seen in New Guinea and the Midwestern USA. Photo by Gregory Bateson, April 30, 1937. Mead-Bateson collection item 204e, Manuscript Division, Library of Congress.

of sequential, interactional analysis? The next section gives some background on the latter.

\subsubsection{Talk in interaction: From audio to video data}

While the use of video recording methodology was developing on one side, the study of talk in interaction had a different trajectory, linked to a 1960s break-away movement in sociology influenced by Garfinkel's ethnomethodology (Garfinkel 1967; 2002; Heritage 1984). Ethnomethodologically minded sociologists argued, contrary to the traditional approach of quantitatively analyzing large data sets based mainly on a priori categories, that the social order is best studied as it emerges through interactions among members of a society. This perspective led Harvey Sacks and his colleagues to create a paradigm for analyzing the minute details of social interactions that has over the years developed into the field of Conversation Analysis (CA) (Schegloff 1968; Sudnow 1972; Sacks et al. 1974; Sacks 1992; Sidnell 2010, among many other sources). 
While some early CA work addressed bodily behavior in interaction (e.g., Schegloff's work on gesture [1984] and body torque [1998], among other studies), due to the ease of recording over the phone, practitioners initially focused to a large extent on telephone interaction, leading to classic work on phone-based practices like call openings (e.g., Schegloff 1968; see discussions in Luke and Pavlidou 2002). This audio-only approach was also sometimes used when participants were co-present, leading to the transcription of conversational sequences with attention to elements like turntaking, pauses, and overlap at an unprecedented level of detail. Today conversation analysts have embraced video data and study all kinds of visual bodily behavior like gesture (Streeck 1993; Mondada 2007) and gaze (Egbert 1996; Kidwell 2005; Rossano et al. 2009) as part of sequential conversational structure (Stivers and Sidnell 2005; Enfield 2009). However, because of CA's historical focus on English and a handful of other languages, its methods are only just beginning to be applied cross-culturally in the way that early anthropological studies of bodily behavior were. Armed not with wax cylinders and cassette recorders but with portable high-definition video cameras, researchers in future paradigms of multimodal interaction analysis are set to enrich CA through confronting the linguistic and cultural diversity emphasized by comparative ethnographic approaches, while providing ethnographically minded fieldworkers with a whole range of tools for sequential analysis to be tried out and adapted to diverse sociolinguistic settings.

\subsubsection{Everyday conversation in ethnographic approaches to language}

Through the 1960s, 1970s, and 1980s, while much of mainstream linguistics was studying decontextualized English sentences, linguistic anthropology continued to emphasize cultural diversity and social context through paradigms like "the Ethnography of Speaking" (or later, "The Ethnography of Communication”) (Hymes 1962; 1974; Gumperz and Hymes 1964; Bauman and Sherzer 1974; 1975). This explicitly relativistic approach was based on "the understanding that speaking, like other systems of cultural behavior - kinship, politics, economics, religion, or any other - is patterned within each society in culture-specific, cross-culturally variable ways" (Bauman and Sherzer 1975: 98). Many studies in this framework focused on the "poetic function" of language (Jakobson 1960), studying formalized speech genres in which cultural variation was salient, like Sherzer's Kuna Ways of Speaking (1983), which comprehensively describes verbal art genres like ritual curing songs and language games, but discusses everyday conversation in less detail. ${ }^{8}$ Like conversation analysts, verbal art researchers developed specialized transcription systems (Tedlock 1983; Sammons and Sherzer 2000), but oriented around ethnopoetic questions rather than questions of turn-taking and sequence 
organization in the technical sense. There has certainly been some discussion of everyday conversation in this framework, but, oddly, ethnographers of communication may have historically generated more empirical information about formalized speech genres around the world than about mundane, informal conversation (cf. this volume, Chapters 19 and 20).

While linguistic anthropology has moved in many new directions since the early days of the ethnography of communication, ${ }^{9}$ its basic concern with linguistic and cultural particularity remains part of the subdiscipline. If this focus on linguistic and cultural diversity is combined with the approach of conversation analysis, which like mainstream linguistics focused mostly on English and a few other languages during the second half of the twentieth century, a whole set of unaddressed questions arises about the cross-cultural scope of previous findings. What we suggest, and what Michael Moerman advocated decades ago when he wondered whether the turn-taking system of Tai-Lue speakers in Thailand resembled that of American English speakers (Moerman 1977, 1988), is the further development of ethnographically informed, cross-linguistic methods in conversation analysis (which some researchers are already developing; see Sidnell 2006; 2007; 2009 and references therein). This "Ethnography of Communication 2.0," while not necessarily abandoning topics like poetics (which can also be addressed with CA methods; see Jefferson 1996), would take up an array of new and unresolved questions about cultural diversity in interactive practices and sequential structures of conversation.

\subsubsection{Conversational actions cross-culturally}

One of the first problems that any program for the cross-cultural study of interaction must confront is the issue of the cross-cultural equivalence of actions like those discussed in terms of "speech acts" (Austin 1962; Searle 1969) or in terms of "conversational actions" (Levinson 2013). Are actions like "requesting" or "promising" things speakers of English do with words? Or should we expect to see versions of these kinds of actions among speakers of different languages all over the world?

Some studies have applied speech act categories cross-linguistically, like those that looked at speech acts like "apologies" in languages as different as Arabic, Persian, Korean, Chinese, Japanese, and Akan. ${ }^{10}$ Much of the work in this area falls into the paradigm called "cross cultural pragmatics" (Blum-Kulka et al. 1989). ${ }^{11}$ Most of these studies were based on interviews, surveys, and discourse completion exercises rather than on the sequential analysis of records of conversational data. A few studies have applied sequential analysis to similar questions, as in Beach and Lindstrom's (1992) comparison of acknowledgment tokens in conversational recordings of Swedish and American English, and Sidnell and Enfield's (2012) study of agreement sequences in Caribbean English Creole, Finnish, and Lao. 
Ethnographic looks at local metalinguistic knowledge can offer interesting takes on the problem of cross-linguistic action types, as in a study by Edwards on insults in Guyanese creole (Edwards 1979), in which he treats "insults" as a cross-linguistic category, but then describes how Guyanese insults are locally split into two named sub-types of insult that might not be translatable into other languages. Anthropologist Michelle Rosaldo critiqued speech act theory in a discussion of Ilongot speech acts (1982) where she argued that the taxonomy of speech acts proposed by Searle (1969) was not cross-linguistically transferable; Searle (2006) later responded that she had misunderstood, arguing that his universal categories need not be found in every culture to be valid. It is increasingly obvious that the best way to settle these kinds of debates and make progress with these questions is to empirically study comparable data sets of social interaction in different languages and societies. In contrast to the elicited and mostly written data considered by many studies in cross-cultural pragmatics, however, observing conversational actions in interaction requires conversation-analytic tools to approach the sequential contexts in which they occur (cf. this volume, Chapter 17).

\subsection{Conversational structures}

The above sections highlight some of the challenges raised by the prospect of cross-linguistically comparative interaction studies, as well as the diverse approaches developed across the social sciences to meet these challenges. A way for researchers to begin to solve these kinds of problems is by building corpora of social interaction that can offer both qualitative and quantitative ways for comparing interactional practices of different peoples around the world, making possible a level of empirical research on natural speech practices that controlled speaking exercises and impressionistic observation cannot equal.

Some work is already heading in this direction. In the following sections we highlight three domains of conversational structure in which there has been some comparative research. From the basic mechanisms of turn-taking and timing we move to the achievement of mutual understanding through other-initiated repair, and from there we branch off into the semiotics of visible behavior. The goals are, first, to show the kinds of structures brought to light by comparative analysis of rich records of conversation, and second, to highlight some of the more salient methodological points from this literature. It will become clear that any researcher with a comparable conversational corpus can ask the same questions asked in these studies to get an idea of how the language they study compares to others - or they can pose new questions and seek collaborators with similar corpora to generate new comparisons. 


\subsubsection{Turn-taking}

A basic structural fact about social interaction is that speakers change and that turns at talk follow each other, forming conversational sequences. Some basic features of turn-taking include a normative rule that one party speaks at a time, as well as principles of turn construction, speaker selection, and turn transition (Sacks et al. 1974). Strongly similar turntaking practices have been found wherever people have looked (Moerman 1977, 1988; Hopper et al. 1990; Lerner and Takagi 1999; Zimmerman 1999; Sidnell 2001; Stivers et al. 2009). So far, claims of deviance from these systematics have not held up to empirical investigation of recorded interactions. For instance, Reisman claimed that conversations in Caribbean Creole English were "contrapuntal" and "anarchic," in direct opposition to the one-speaker-at-a-time rule proposed by Sacks and colleagues (Reisman 1974: 113). If true, this would imply a turn-taking system that is structured very differently from the one outlined by Sacks et al. (1974). Sidnell (2001) investigated tape-recorded multi-party conversations in a Caribbean English Creole carefully matched to the variety described by Reisman, and showed that these conversations are in fact orderly and that participants do monitor talk in progress to determine possible turn completion points, suggesting that the turn-taking aspects of informal conversation "are not open to a great deal of cultural diversification" (2001: 1287).

Recent comparative work provides evidence for a combination of strong similarities with measurable cultural variation. In a study of ten languages of varied type, geographical location, and cultural setting, Stivers et al. (2009) found strong commonalities in turn-taking behavior. Timing the response offsets in yes/no question-response sequences, they found that all languages showed a similar distribution of response offsets, with the highest number of transitions occurring between 0 and 200 milliseconds. They concluded that the distribution in the ten languages "reflects a target of minimal overlap and minimal gap between turns" (Stivers et al. 2009: 10589). At the same time, they documented measurable cultural differences in the mean response across languages. Danish has the slowest average response time $(469 \mathrm{~ms})$, while Japanese had the fastest (7ms). Are differences like these perhaps the grounds for earlier ethnographic reports of cultural variability? As Stivers et al. point out, the Danish finding is in line with field reports for Scandinavian languages, which state that there can be long silences between turns (Lehtonen and Sajavaara 1985; as cited in Stivers et al. 2009). On the other hand, the very fast response times for Japanese are not in line with ethnographic reports, which generally emphasize the value placed on silence in Japanese conversation (Gudykunst and Nishida 1994; as cited in Stivers et al. 2009). This shows the importance of a continuous interaction of theory and empirical work in this field. 
Comparative research in the domain of turn-taking provides us with a number of ingredients for our toolkit of cross-linguistically comparative studies of social interaction. The work on turn-taking remains one of the strongest demonstrations that conversation exhibits order, and that this order can be discovered and described on the basis of records of conversation. Even though original description of the organization of turntaking was based on English, subsequent research has shown that it is a system with a strong claim to cross-linguistic generality. ${ }^{12}$ The interaction between claims based on unrecorded observations and empirical verification shows the importance of basing comparative claims on comparable materials. Conversation-analytic work provides a number of useful methodological principles here. One is the requirement that analyses be grounded in data that are available for repeated inspection, to make sure that observations can be independently checked and replicated. Another is what we will call the natural control method. This method rests on the insight that the sequential structure of interaction can be used as a natural control, enabling systematic comparison across linguistic-cultural settings (Zimmerman 1999:198). Stivers et al. (2009) used this method in their study of the timing of turn-taking across languages: rather than haphazardly measuring the timing of any kinds of turn-transitions across corpora, they selected one specific sequential environment that occurred in all of the languages studied: the transition from question to response in a question-answer sequence. To determine whether this sequential environment was representative of turn-transitions in general, as a further control, they examined turn-transitions in a corpus of Dutch conversations, and found no difference between response times after questions and non-questions (Stivers et al. 2009: 10588). Thus, by using sequential environment as a natural control over the data, it is possible to carry out fine-grained qualitative analysis as well as large-scale quantitative studies, and to discover both candidate universals and subtle cultural variation. The following section illustrates the natural control method by comparing three instances of another sequence type, "other-initiated repair," showing how it provides a context for comparison across three unrelated languages.

\subsubsection{Repair}

Wherever people communicate, we can expect to find mechanisms for repair: ways of dealing with problems of speaking, hearing, and understanding (Schegloff 2006). Early work in conversation analysis detailed the basic organization of repair in conversation (Schegloff et al. 1977). Distinguishing who initiates repair (self or other), who carries it out (self or other), and where it is done (same turn, transition space, or subsequent turn), this work mapped out the possibility space of repair as 
realized in a corpus of English conversation. A comparative study by Moerman (1977) found repair to be similarly organized in a corpus of Tai/Lue conversation. Based on this, Moerman concluded that the organization of repair is essentially generic: "Since Tai is historically unrelated to English, and since a northern Thai village is (by most standards) socioculturally quite different from America, the detailed, systemic, and massive parallels between these two corpora support a claim that the domain described by Sacks, Schegloff and Jefferson is conversation - without respect to the language, nation, class, or culture in which it occurs" (Moerman 1977: 875). At the same time, he noted that "one gets the impression of languages with quite different resources being mobilised to do the same conversational jobs" (ibid.). The study of repair in conversation thus started out in an explicitly comparative fashion, and with attention to repair as at once generic in organization and potentially locally inflected (cf. Sidnell 2007).

The striking similarity of some of the basic strategies for repair can be demonstrated using the three conversational extracts below. Taken from unrelated languages spoken on three different continents (Siwu, NigerCongo, Ghana; Lao, Tai-Kadai, Laos; Cha'palaa, Barbacoan, Ecuador), these are examples of the repair strategy that has been called open-class otherinitiated repair (Drew 1997): repair initiated not by self but by other, and initiated on some prior talk while leaving open what or where in the turn the problem is.

Extract 2. Siwu (Ghana) [Maize3_758330a]

1 A mámà so ba.

mama QT come

'Mama says “come”!

2 B aá?

OIR.INTJ

'Huh?'

3 A mámà so ba.

mama QT come

'Mama says “come”!

Extract 3. Lao (Laos) [CONV_050815c_03.10]

1 A nòoj4 bòò1 mii2 sùak4 vaa3 nòòj4

PSN NEG have rope QPLR.INFER PSN

'Noi, don't you have any rope, Noi?'

2 B haa2?

OIR.INTJ

'Huh?'

3 A bòò mii2 sùak4 vaa3

NEG have rope QPLR.INFER

'Don't you have any rope?' 
Extract 4. Cha'palaa (Ecuador) [CHSF2012_01_20S1_1457697]

\section{A chundenashin}

sit-PL-POS-AFF

'(youpl are) sitting'

2 В $a a ?$

OIR.INTJ

'Huh?'

3 A ñuilla kera' chundenahshin

2PL see-SR sit-PL-POS-AFF

'YoupL (can be clearly) seen sitting.'

All three sequences come in the same three-turn structure. This structure (in which one participant initiates repair by pointing out some trouble in a prior turn and the other solves it in the next turn) is one of those sequential environments that can be located across different corpora and therefore is a fruitful locus for comparison. Following the natural control method described above, by keeping the sequential environment constant, one can compare the different formats for initiating repair available within and across languages, and the relations between types of trouble, repair initiations, and repair solutions. The three data extracts above represent the most common sequence type for open-class other-initiated repair in Siwu, Lao, and Cha'palaa. ${ }^{13}$ They not only share the same three-turn structure but also show similarities in the formats of repair initiation and solution. For instance, in all three, the result of the repair initiation is that some material of the first turn is repeated by $\mathrm{A}$ in the third turn. ${ }^{14}$ But it is the form of the interjection that is most strikingly similar in the three languages: a monosyllable with a low front vowel, viz. aa in Cha'palaa, aá in Siwu, and haa2 in Lao. On the face of it, this would suggest that perhaps this form is not quite a word, but "a virtually pre-lexical grunt," as Schegloff (1997: 506) characterizes the phonetically similar English huh? [hã]. A striking difference, however, is that the intonation of the Cha'palaa interjection is falling, whereas it is rising in Siwu and Lao. The key is that in all three languages, the intonation on the item is understood to signify questioning intonation. ${ }^{15}$ Thus even though on the surface, pitch patterns differ, the more revealing generalization is that the interjections for initiating repair appear to share their pitch patterns with the interrogative prosodic systems of the languages (Dingemanse et al. 2013).

Amidst the striking similarities, this, then, is a first locus of variation: the tuning of techniques of repair to the linguistic resources of a language. This tuning has been observed at several levels of linguistic organization, and in different types of conversational repair. For instance, in the context of self-repair, Fox et al.'s (1996) comparison of English and Japanese brings to light a difference due to morphosyntax. In Japanese self-repairs, speakers are sometimes found to replace one inflectional ending of a verb with another, whereas this is not observed in English. 
Fox et al. (1996) connect this to several differences in the verbal morphology of English and Japanese: the fact that Japanese verb suffixes are often full syllables (e.g., -shi, -soo) whereas in English, they often are not (e.g., -ed $[\mathrm{t}] /[\mathrm{d}],-s[\mathrm{~s}])$; the fact that Japanese verb suffixes tend to have unitary meanings, whereas English verb suffixes are more semantically complex; and the fact that Japanese verb suffixes do not agree, whereas English verb suffixes do. English verb suffixes, they conclude, "are more tightly 'bonded' to the verb than are verb endings in Japanese and hence are less available for individual replacement” (Fox et al. 1996: 203).

Another locus of variation in repair techniques has been proposed to lie in differences in social norms. In a study of gossip in Nukulaelae Tuvaluan (Austronesian, Tuvalu), Besnier says that the repair initiation technique of providing a candidate understanding is "conspicuously absent" (Besnier 1989: 324). He attributes this to a social norm in this Polynesian island community to the effect that "interactants avoid guessing what is on another person's mind” (1989: 322). Social norms of this kind have been described for other Polynesian societies too (e.g., Ochs 1984; Duranti 1988 on Samoa; Duranti 2008), and so this is potentially a significant gap. However, Besnier's discussion equivocates between describing the unavailability of candidate understandings as a fact about the Nukulaelae genre of "gossip interactions" (1989: 318, 336) and as a fact about "Nukulaelae conversation" in general (1989: 322-5). These possibilities need to be kept apart. The first would involve the claim that the use or avoidance of certain practices are among the things that can serve as markers of genres or can be constitutive of such genres. The second, stronger claim would be that the inventory of repair practices itself is modified, so that the technique of presenting a candidate understanding is wholly unavailable to Nukulaelae speakers. Besnier's data provides grounds for the first claim but not the second. The data extracts cited in his paper to demonstrate the workings of other-initiated repair do in fact contain candidate understandings: in extract 11, one speaker presents a candidate understanding te fafa? "a fathom?" followed by a nonverbal confirmation by the other (Besnier 1989: 324), and in extract 12, a speaker presents a person reference as a candidate understanding, glossed as “(you mean) Neli?" (Besnier 1989: 324). So it appears that the technique of presenting a candidate understanding is available in Nukulaelae conversation, but that not using this technique, or using it less frequently, may be a feature constitutive of gossip interactions. A similar but inverse situation is the use of apology-based expressions for initiating repair in English, which has been observed - in a collection of 101 cases - to occur predominantly in situations where social asymmetries are foregrounded (Robinson 2006), and only very rarely in informal social interaction.

What lessons can we draw from the cross-linguistic study of repair practices? So far, the basics of the organization of repair appear to show 
remarkable similarities across languages, but at the same time, crosslinguistic differences that can be linked to differences in linguistic resources; and there have been suggestive claims of the possible relation between social norms and repair practices. With regard to this relation, it is worth reiterating that conversation is not a passive code influenced by social norms, but that its production can be constitutive of these norms: the choice for one repair technique over another may be one among several signals indicating, for instance, that interlocutors are now "doing gossip interaction" or "doing formality." More broadly, what the divergent claims about the shaping of repair practices suggest is that there is a need to establish common standards of evidentiary requirements and data collection. At the very minimum, this includes empirically grounding the analysis in data that is available for repeated inspection, and providing information about the nature and representativeness of the corpus and the number of cases studied. Only with such information, does proper comparison become possible.

\subsubsection{Cultural variation and multimodal interactional resources}

Many sequential structures, like the repair sequences discussed above, can to some extent be effectively compared in terms of spoken turns alone, but the findings of a flourishing interdisciplinary field of gesture studies over recent decades has shown us that spoken language and body behavior are two integrated aspects of a single process (Kendon 1980; McNeill 1992; and many others), and are packaged together in "composite utterances" (Enfield 2009). Sequences do not just exist as "turns," in the sense that turn-constructional units have been traditionally seen as spoken elements, but can be thought of as consisting of more complex multimodal "moves" (Goffman 1981; Enfield 2009, in press). Conversation analysts are increasingly studying the visual mode's potential for simultaneity with talk that allows for a number of practices that run together with, but parallel to, turn-taking. Speakers can use gaze to help accomplish sequence closure (Rossano 2013). They can use posture to manage engagements in multiple courses of action (Schegloff 1998). They can use pointing to project upcoming turns (Mondada 2007). These observations, when considered together with the cross-cultural questions that motivate this chapter, lead us to ask to what extent such practices can be expected to vary according to cultural convention, or to what extent they are part of a general semiotics of social interaction for speakers of any language.

Ethnographers have long been interested in cultural variation in gestural and bodily behavior, ${ }^{16}$ as seen for instance in the early cross-cultural film studies cited above (for a recent review, see Kita 2009). While there has been relatively little systematic cross-linguistic comparison in this area since that early work, some recent work has shown, for example, a 
degree of cultural variation in gaze behavior (Rossano et al. 2009). Research on pointing shows it to be a great example of a practice that occurs around the world (Kita 2003), although with cross-cultural variation. For example, while most speakers of English canonically point with the index figure, speakers of other languages may use other hand shapes or other body parts entirely, such as the lips (see for instance Sherzer 1973 on the Kuna of Panama and Enfield 2001 on Lao). What are the implications of this kind of cultural variation for cross-cultural interaction studies?

The following excerpt (Excerpt 5) from a household interaction among speakers of Cha'palaa provides a partial answer to this question. In this example, an instance of lip-pointing constitutes a distinct move in the sequential structure of a conversation. If we were to attend only to the spoken turns, this exchange between two parents and their son would seem odd, since the boy's questions in lines 2 and 4 appear to be ignored, followed only by pauses in the talk. However, analysis of the video shows that the question in line 2 , the repair initiator "to whom?," was followed in 3 by the mother's lip point, directed at the father (Figure 18.3a), a perfectly fitted response of a person reference to a "who" question. Shortly thereafter, another culturally conventionalized bodily practice comes into play, because the boy offers a candidate understanding of his mother's lip point ("to father?") which is then confirmed in line 5 through a brief raising of the eyebrows, or "eyebrow flash" (Grammer et al. 1988; Eibl-Eibesfeldt 1989: 453ff.), closing the sequence by confirming the candidate repair solution in 4 (Figure 18.3b).

Extract 5. Cha'palaa (CHSF2012_01_20S6_2071407)

1 Mother ajpele-nu ka'-ta-di-'mityaa ee-tyu-i tii-ti-ee

belt-ACC get-have-POs-because send-NEG-EGo say-say-DECL

'Since he was holding a belt they said not to send him.'

2 Bоу mu-nu-n

who-ACC-Q

'To whom?'

3 Mother ((lip point towards father)) ((pause before next spoken TCU: 1.8s))

4 Boy apa-nu-u?

father-ACC-Q

'To father?'

5 Mother ((eyebrow flash)) ((pause before next spoken TCU: 2.5s))

Speakers of English in a similar sequence might have drawn on their own conventionalized gestural resources, like index finger pointing for person reference and head nodding for confirmation (Schegloff 1982; Whitehead 2011). Despite the fact that gestural elements are not generally considered part of turn-constructional units with respect to the turn-taking system as it is technically understood, in the excerpt above these practices are indeed parts of the sequential structure. Studying cross-cultural variation 

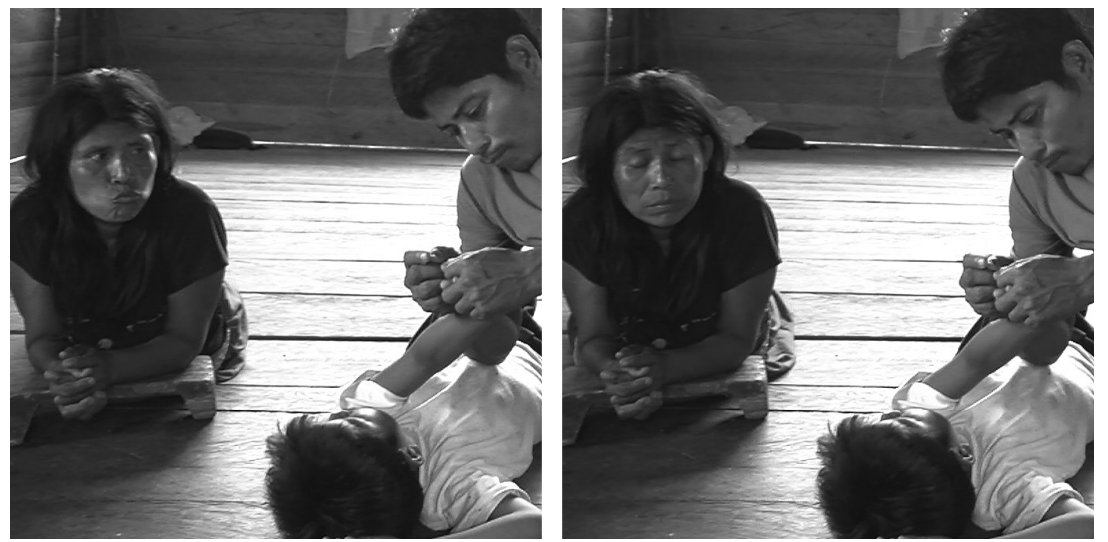

Figure 18.3 Two visual-gestural signs in Cha'palaa

in gestural practices and their interactional uses is one angle in the persistent problem of how to approach elements other than spoken turns within the turn-taking system.

Halfway around the world from Ecuador, Levinson has observed eyebrow flashes as used as confirmations among speakers of Yélî Dnye in Papua New Guinea, as in this question-answer sequence (Levinson 2006: 60):

Extract 6. Yélî Dnye (R02_V4 00:03:27)

$1 \mathrm{~J}$ mu dmââdî ngêe? cha w:ee?

that girl TP you understand

'That girl, you see?'

$2 \mathrm{R}$ ((eyebrow flash)) éé ((confirmation)) 'Yes.'

The fact that eyebrow flashing for confirmation and lip pointing for reference are practices that pop up in different languages around the world leads to a series of questions that should be a part of cross-cultural interaction studies: What functions do specific local bodily or multimodal practices have in conversation? To what extent is there formal and functional variation in multimodal practices cross-culturally? Why do similar practices appear in completely unrelated languages? What are the relative roles of natural meaning and conventionalization in the development of these practices? Further research in this area stands to teach us much more about the intersection between cross-cultural and multi-modal questions. ${ }^{17}$

\subsection{Conclusions}

Tools for the comparative study of social interaction are divided among different disciplines, and so a proposal for undertaking this project means 
assembling an eclectic toolkit. From linguistic anthropology, we need the focus on linguistic diversity and methods for analyzing language usage in different cultural settings. From sociocultural anthropology, we need ways to tap into the rich cultural understandings that enter into the construction and interpretation of everyday social interaction. From conversation analysis, we need the methods, concepts, and transcription practices developed for studying sequential structures of talk. We also need the resources of descriptive linguistics for understanding the basic morphosyntactic and phonological elements that make up the linguistic parts of interactional structures. Corpus linguistics offers methods for dealing with quantitative and comparable sets of data. And in addition to all of these interdisciplinary tools, we need the attention to visual bodily behavior provided by gesture studies and related fields, and methods for analysis of video data that complement those for analysis of talk.

The material reviewed here can be summed up in five key methodological principles for cross-cultural comparative interaction studies. Studies in this field should be:

(1) ECOlogically VAlid. Language and social interaction are best studied in their natural-cultural habitat: everyday face-to-face interaction, the primordial home of language. Special ways of speaking only become special against a baseline, and understanding the workings of this baseline is a crucial part of understanding language use in all its forms.

(2) ETHNOGRAPHICALly EnRICHED. Moments of talk never take place in a vacuum: their occurrence is embedded in, their interpretations enriched by, social, cultural, and biographical contexts. Records of interaction are artifacts that for most purposes can only be analyzed with reference to knowledge based on long-term experience in the society.

(3) EMPIRICALlY GROUNDED. Claims about interaction should be as directly accountable to the data as possible. They should be based on rich records of data that are available for repeated inspection.

(4) MULTI-MODAL. The bodily elements of interaction and the semiotics of visible behavior are part and parcel of language use around the world. This is the form in which language evolved and it therefore commands our primary attention.

(5) COMPARABlE. Claims purporting to go beyond single cases should always be based on comparable collections of data. It is not only important to collect data in comparable settings, but also to carry out comparison in carefully matched sequential environments, using the natural control method as a way to ensure that like is compared with like.

Studying conversation across cultures means taking a perspective on social interaction that is committed to linguistic as well as anthropological 
insights. We hope to have shown in this chapter that a truly cross-cultural comparative study of social interaction is within reach. The interdisciplinary approach outlined here offers promising avenues for not being overwhelmed by diversity but for learning from it. Similarly to the way that the cumulative record of grammatical descriptions of the world's languages made linguistic typology possible, as fieldworkers (often together with community members) record and transcribe more hours of conversational video data from diverse languages and settings, comparative studies of interaction will become more and more practical, and yield greater insights.

\section{Acknowledgments}

We thank Giovanni Rossi, Gunter Senft, and Maria Luz Garcia for helpful comments, and also the editors (Nick Enfield, Paul Kockelman, and Jack Sidnell) for giving us guidance at various stages of the process. We would also like to thank the communities in our respective fieldsites (AkpafuMempeasem, Ghana and Tsejpi, Ecuador). This research was funded by the Max Planck Society for the Advancement of Science and the European Research Council grant 240853.

\section{Notes}

1. In linguistics the concept of discrete languages versus dialect continua is equally problematic, but linguists generally use the concept in an informed and pragmatic way and have been able to make progress with cross-linguistic comparison. Bashkow advocates adapting some approaches from dialectology into cultural anthropology, pointing out that the fact that language boundaries are indeterminate can be dealt with pragmatically: "The lesson dialectologists draw from [unclear boundaries] is not that distinguishable languages do not exist, but that the way one draws their boundaries depends on the particular language features one chooses to emphasize" (2004: 52). We feel it is better to use the term pragmatically in this way, since avoidance of the word "culture" often leads to its substitution by other words referring to the same kinds of differences across social groups, somewhat like a speaker of an Australian language whose local norms do not permit her to mention the name of a specific relative but who can choose other more indirect words for referring to the same person.

2. Abu-Lughod points out that in anthropology "Americans who study Americans" (1991: 139) have been considered odd, but this claim is increasingly outdated. In other disciplines like sociology and psychology the norm has long been to research with members of the same culture as the researchers themselves, leading to general theories of 
human behavior based on just one or a few cultures (Henrich et al. 2010). In the interest of keeping cultural concerns on the table, it may be better to risk glossing over some complexity and heterogeneity if the payoff is avoiding ethnocentrism.

3. This extract exemplifies the transcription conventions for representing conversation we use in this chapter (adapted from Jefferson 2004): pauses are marked with decisecond precision in single brackets (1.0), the beginnings and ends of overlapping turns are marked using [square brackets], non-verbal behaviour is described in ((double brackets)), uncertain hearings/readings are marked using (single brackets), and lengthening is marked with a colon. Speaker identifications and names mentioned in the conversation are anonymized where necessary.

4. Abbreviations used in glosses: ACC accusative, AFF affirmative, CM noun class marker, COM comitative, DECL declarative, EGO egophoric, ING ingressive, INTJ interjection, NEG negation, OIR other-initiated repair, PL plural, PLN place name, POS positional, PSN personal name, REL relative (pronoun), SCR subject cross-reference marker, SG singular, SR same referent, TP topic, Q question, QPLR.INFER polar question proposition inferred, QT quotative.

5. With respect to the long debate in anthropology about the ethnographer's membership status with respect to the field site, we believe that focused ethnography is useful for both "insiders" and "outsiders" in any social setting.

6. This despite the fact that in ethnomethodology (in many ways a cognate discipline to conversation analysis), researchers have commonly used ethnographic fieldwork as a way of acquiring membership competencies in order to study local routine practices (Garfinkel 1967; Garfinkel and Wieder 1992; ten Have 2002).

7. In his review of this period, Ruby points out that Boas was "one of the first anthropologists, and perhaps the first social scientist anywhere, to use the motion picture camera to generate data in natural settings (as opposed to a laboratory) in order to study gesture, motor habits, and dance as manifestations of culture" (1980: 7). Several of Boas' students also adopted these methods; for example, Zora Neal Hurston used a film camera for collecting African American folklore (Charnov 1998).

8. This approach did not ignore dialogic aspects of language, but considered these mainly in terms of poetics, like in Urban's discussions of "backchannels" (or "continuers") and of ceremonial dialogs in which listeners to narratives repeat syllables in disregard of the usual turnconstructional units (Urban 1986).

9. Duranti (2003) describes the current paradigm in linguistic anthropology as one that turns away from some of the concerns of the ethnography of communication and toward some of the socio-political questions current in social anthropology (e.g., the boom in "language ideology" studies). 
10. Apology studies include: Akan (Obeng 1999), Persian (Shariati and Chamani 2010), Jordanian Arabic (Bataineh and Bataineh 2006), Sudanese Arabic (Nureddeen 2008), Japanese (Barnlund and Yoshioka 1990), Korean and Chinese (Guan et al. 2009). Other kinds of actions that have been studied include “requests” in Swahili (D’hondt 1992), Spanish (Márquez-Reiter 2000), Japanese (Fukushima 2003), and Mandarin Chinese and Korean (Rue 2008); and "compliments" and "compliment responses" in Japanese (Barnlund and Araki 1985), Finnish (Ylänne-McEwen 1993), Chinese (Tang and Zhang 2009), and Arabic (Nelson et al. 1996).

11. Some work in this paradigm was motivated by the goal of identifying problems in interethnic communication rooted in cross-cultural differences in interactive practices (e.g., Gumperz 1982).

12. The robust universality of turn-taking has led to speculation about its origins. One proposal is that the turn-taking system may be a "speciesspecific adaptation to the contingencies of human social intercourse" (Sidnell 2001). While this wording seems to suggest a native endowment (as does Levinson's [2006: 44] "human interaction engine"), it is an open question whether turn-taking abilities should be attributed to biological or to cultural evolution or to a combination of both. Turntaking behaviors are found in some non-human primates (e.g., Campbell's monkeys, Lemasson et al. 2011; vervet monkeys and rhesus macaques, Hauser 1992), though not in chimpanzees (Arcadi 2000). Although the particulars of the human turn-taking system are clearly organized with reference to human linguistic abilities (such as the capacity to construct turns from linguistic units and to recognize turn-constructional units as complete), turn-taking itself may be an evolutionarily optimal solution to the generic problem of bidirectional communication, found not just in humans but in many other species (Yoshida and Okanoya 2005; Colman and Browning 2009).

13. The extracts are drawn from a corpus of about eight hours per language of video recordings of maximally informal interaction, typically between people who know each other well (family, friends, neighbors). Besides the interjection format described here, the other two formats for open-class other-initiation of repair in these three languages are, in order of frequency, a question-word format (be: 'what?' in Siwu, i 'nay 'what?' in Lao, ti 'what?' in Cha'palaa) and a non-verbal format (combining leaning forward with eyebrow action) (Enfield et al. 2013).

14. The exact operation of the repair solution is subtly different in the three cases, so that the extracts demonstrate three points about repetition in repair solutions cross-linguistically. The Siwu example shows that repetition can be exactly verbatim. The Lao example demonstrates the phenomenon known as "dispensability" (Schegloff 2004): items linking the trouble source turn to the discourse context (such as 
the doubly occcurring address term Noi in Extract 3 line 1) can be left out in the repair solution. The Cha'palaa example shows that repair solutions may involve an analysis of the trouble: more information may be included besides the repeated material, displaying an orientation to a possible problem of underspecification. Though illustrated here with material from different languages, we have observed these three phenomena within each language as well.

15. Questioning intonation is marked in our transcripts using “?”. Note that in this respect our transcription deviates from CA transcription, in which the question mark is used to mark "rising intonation," based on English.

16. For example, in the 1930s and 1940s David Efron asked questions about the cultural basis for gesture as part of a Boasian argument against the racial or hereditary determination of gestural patterns, showing that while immigrant populations in the US differed systematically from each other in terms of both form and frequency of gesture, by the second generation the groups were indistinguishable from each other, thus validating a cultural explanation for the difference (Efron 1941).

17. Languages that are expressed entirely in the visual mode have special significance for cross-cultural interaction studies, and a program of cross-linguistic conversation analysis should also be sure to take into account the diversity of the world's sign languages. We do not have space to do justice to the issues raised by cross-modal comparison here, but one important question that arises is how turn-taking can be studied in languages whose "spoken" elements are in the visual mode. There has been little research on the topic of turn-taking in signed languages (e.g., Baker 1977; Coates and Sutton-Spence 2001), but tentatively it would seem that signed languages do operate with a turn-taking system similar to that of spoken languages.

\section{References}

Abu-Lughod, Lila. 1991. Writing Against Culture. In Recapturing Anthropology: Working in the Present, ed. Richard G. Fox, 137-62. Santa Fe: School of American Research Press.

Antaki, Charles. 2012. Affiliative and Disaffiliative Candidate Understandings. Discourse Studies 14(5): 531-47. doi:10.1177/1461445612454074.

Arcadi, Adam Clark. 2000. Vocal Responsiveness in Male Wild Chimpanzees: Implications for the evolution of language. Journal of Human Evolution 39(2): 205-23. doi:10.1006/jhev.2000.0415.

Austin, J. L. 1962. How to Do Things with Words. Oxford: Clarendon Press.

Baker, C. 1977. Regulators and Turn-taking in American Sign Language Discourse. On the Other Hand. http://ci.nii.ac.jp/naid/10021343089/. 
Barnlund, Dean C., and Shoko Araki. 1985. Intercultural Encounters: The Management of Compliments by Japanese and Americans. Journal of Cross-Cultural Psychology 16(1): 9-26. doi:10.1177/0022002185 016001002.

Barnlund, Dean C., and Miho Yoshioka. 1990. Apologies: Japanese and American Styles. International Journal of Intercultural Relations 14(2): 193-206. doi:10.1016/0147-1767(90)90005-H.

Bashkow, Ira. 2004. A Neo-Boasian Conception of Cultural Boundaries. American Anthropologist 106(3): 443-58. doi:10.1525/aa.2004.106.3.443.

Bataineh, R., and R. Bataineh. 2006. Apology Strategies of Jordanian EFL University Students. Journal of Pragmatics 38(11): 1901-27. doi:10.1016/ j.pragma.2005.11.004.

Bateson, Gregory, and Margaret Mead. 1951. Bathing Babies in Three Cultures. $16 \mathrm{~mm}$ BW film, 11 minutes.

Bauman, Richard, and Joel Sherzer, eds. 1974. Explorations in the Ethnography of Speaking. London,New York: Cambridge University Press.

1975. The Ethnography of Speaking. Annual Review of Anthropology 4: 95-119.

Beach, Wayne A. 1990. Searching for Universal Features of Conversation. Research on Language and Social Interaction 24: 351-68. doi:10.1080/ 08351819009389347.

Beach, Wayne A., and Anna K. Lindstrom. 1992. Conversational Universals and Comparative Theory: Turning to Swedish and American acknowledgment tokens in interaction. Communication Theory 2(1): 24-49. doi:10.1111/j.1468-2885.1992.tb00027.x.

Besnier, Niko. 1989. Information Withholding as a Manipulative and Collusive Strategy in Nukulaelae Gossip. Language in Society 18(3): 315-41. doi:10.1017/S0047404500013634.

Birdwhistell, Ray L. 1952. Introduction to Kinesics: An Annotation System for Analysis of Body Motion and Gesture. Dept. of State, Foreign Service Institute.

Blum-Kulka, Shoshana, Juliane House, and Gabriele Kasper. 1989. CrossCultural Pragmatics: Requests and Apologies. Norwood, NJ: Ablex Pub. Corp.

Charnov, Elaine S. 1998. The Performative Visual Anthropology Films of Zora Neale Hurston. Film Criticism 23(1): 38-47.

Coates, Jennifer, and Rachel Sutton-Spence. 2001. Turn-taking Patterns in Deaf Conversation. Journal of Sociolinguistics 5(4): 507-29. doi:10.1111/ 1467-9481.00162.

Cohen, Emma. 2008. What is Spirit Possession? Defining, comparing, and explaining two possession forms. Ethnos 73(1): 101-26. doi:10.1080/ 00141840801927558.

Colman, Andrew M., and Lindsay Browning. 2009. Evolution of Cooperative Turn-taking. Evolutionary Ecology Research 11: 949-63.

D’hondt, Sigur. 1992. A Request in Swahili: On conversation analysis and non-western societies. In SKY Yearbook of the Linguistic Association of Finland, ed Maria Vilkuna, 127-40. 
Davis, Martha. 2001. Film Projectors as Microscopes: Ray L. Birdwhistell and Microanalysis of Interaction (1955-1975). Visual Anthropology Review 17(2): 39-49.

Dingemanse, Mark, Francisco Torreira, and N. J. Enfield. 2013. Is “Huh?” a Universal Word? Conversational infrastructure and the convergent evolution of linguistic items. PLoS One 8(11): e78273. doi:10.1371/jour nal.pone.0078273.

Drew, Paul. 1997. "Open" class repair initiators in response to sequential sources of trouble in conversation. Journal of Pragmatics 28: 69-101.

Duranti, Alessandro. 1988. Intentions, Language, and Social Action in a Samoan Context. Journal of Pragmatics 12(1): 13-33. doi:10.1016/03782166(88)90017-3.

2003. Language as Culture in U.S. Anthropology: Three Paradigms. Current Anthropology 44(3): 323-47. doi:10.1086/368118.

2008. Further Reflections on Reading Other Minds. Anthropological Quarterly 81(2): 483-94. doi:10.1353/anq.0.0002.

Edwards, Walter F. 1979. Speech Acts in Guyana: Communicating Ritual and Personal Insults. Journal of Black Studies 10(1): 20-39.

Efron, David. 1941. Gesture, Race and Culture: A tentative study of the spatiotemporal and "linguistic" aspects of the gestural behavior of eastern Jews and southern Italians in New York City, living under similar as well as different environmental conditions. The Hague: Mouton.

Egbert, Maria M. 1996. Context-Sensitivity in Conversation: Eye gaze and the German repair initiator bitte? Language in Society 25(4): 587-612. doi:10.1017/S0047404500020820.

Eibl-Eibesfeldt, Irenäus. 1979. Human Ethology: Concepts and implications for the sciences of man. Behavioral and Brain Sciences 2(1): 1-57.

1989. Human Ethology. New York: Aldine De Gruyter.

Enfield, N. J. 2001. "Lip-pointing": A discussion of form and function with reference to data from Laos. Gesture 1(2): 185-212.

2009. The Anatomy of Meaning: Speech, Gesture, and Composite Utterances. Cambridge: Cambridge University Press.

In press. A "Composite Utterances" approach to meaning. In Handbook Body - Language - Communication, ed Cornelia Müller, E. Fricke, Alan Cienki, and David McNeill. Berlin: Mouton De Gruyter.

Enfield, N.J., Tanya Stivers, and Stephen C. Levinson. 2010. Questionresponse sequences in conversation across ten languages: An introduction. Journal of Pragmatics 42(10): 2615-19. doi:10.1016/j.pragma.2010. 04.001.

Field, Margaret J. 1969. Spirit Possession in Ghana. In Spirit Mediumship and Society in Africa, ed J. Beattie and John Middleton, 3-13. London: Routledge and Kegan Paul.

Fox, Barbara A., Makoto Hayashi, and Robert Jasperson. 1996. Resources and Repair: A cross-linguistic study of syntax and repair. In Interaction and Grammar, ed Elinor Ochs, Emanuel A Schegloff, and 
Sandra A Thompson, 185-237. Cambridge: Cambridge University Press.

Fukushima, Saeko. 2003. Requests and Culture: Politeness in British English and Japanese. Bern, New York: P. Lang.

Garfinkel, Harold, ed. 1967. Studies in Ethnomethodology. Englewood Cliffs, NJ: Prentice-Hall.

2002. Ethnomethodology's Program: Working Out Durkheim's Aphorism. Rowman and Littlefield.

Garfinkel, Harold, and D. Lawrence Wieder. 1992. Two Incommensurable, Asymmetrically Alternate Technologies of Social Analysis. In Text in Context: Studies in Ethnomethodology, ed. Graham Watson and Robert M. Seiler, 175-206. Newbury Park, CA: Sage.

Goffman, Erving. 1981. Forms of Talk. Philadelphia: University of Pennsylvania Press.

Goodwin, Charles, and John Heritage. 1990. Conversation Analysis. Annual Review of Anthropology 19: 283-307.

Grammer, Karl, Wulf Schiefenhövel, Margret Schleidt, Beatrice Lorenz, and Irenäus Eibl-Eibesfeldt. 1988. Patterns on the Face: The eyebrow flash in crosscultural comparison. Ethology 77(4): 279-99. doi:10.1111/ j.1439-0310.1988.tb00211.x.

Guan, Xiaowen, Hee Sun Park, and Hye Eun Lee. 2009. Cross-cultural Differences in Apology. International Journal of Intercultural Relations 33(1): 32-45. doi:10.1016/j.ijintrel.2008.10.001.

Gudykunst, William B., and Tsukasa Nishida. 1994. Bridging Japanese/North American Differences. Thousand Oaks, CA: Sage.

Gumperz, John. 1982. Discourse Strategies. Cambridge/New York: Cambridge University Press.

Gumperz, John Joseph, and Dell H. Hymes. 1964. The Ethnography of Communication. American Anthropological Association 66(6), part 2 (Special Issue).

Hall, Edward T. 1963. A System for the Notation of Proxemic Behavior. American Anthropologist 65(5): 1003-26.

Hauser, Marc D. 1992. A Mechanism Guiding Conversational Turn-taking in Vervet Monkeys and Rhesus Macaques, ed. Tsukasa Nishida, Frans B. M. de Waal, William C. McGrew, P. Marler, and M. Pickford. Topics of Primatology 1: 235-48.

ten Have, Paul. 2002. The Notion of Member is the Heart of the Matter: On the Role of Membership Knowledge in Ethnomethodological Inquiry. Forum Qualitative Sozialforschung / Forum: Qualitative Social Research 3 (3). www.qualitative-research.net/index.php/fqs/article/view/834.

Henrich, Joseph, Steven J. Heine, and Ara Norenzayan. 2010. The Weirdest People in the World? Behavioral and Brain Sciences 33(2-3): 61-83. doi:10.1017/S0140525X0999152X.

Heritage, John. 1984. Garfinkel and Ethnomethodology. Cambridge/New York: Polity Press. 
1990. Intention, Meaning and Strategy: Observations on constraints on interaction analysis. Research on Language and Social Interaction 24: 311. doi:10.1080/08351819009389345.

Hopper, Robert. 1990. Ethnography and Conversation Analysis after Talking Culture. Research on Language and Social Interaction 24: 161. doi:10.1080/08351819009389336.

Hopper, Robert, Nanda Doany, Michael Johnson, and Kent Drummond. 1990. Universals and Particulars in Telephone Openings. Research on Language and Social Interaction 24: 369-87. doi:10.1080/08351819009389348.

Hymes, Dell. 1962. The Ethnography of Speaking. In Anthropology and Human Behavior, ed. Thomas Gladwin and William C. Sturtevant, 13-53. Washington, DC.

1974. Foundations in Sociolinguistics: An Ethnographic Approach. University of Pennsylvania Press.

Jacknis, Ira. 1988. Margaret Mead and Gregory Bateson in Bali: Their Use of Photography and Film. Cultural Anthropology 3(2): 160-77.

Jakobson, Roman. 1960. Linguistics and Poetics. In Style in Language, ed Thomas A. Sebeok, 350-77. Cambridge, MA: MIT Press.

Jefferson, Gail. 1996. On the Poetics of Ordinary Talk. Text and Performance Quarterly 16(1): 1-61.

2004. Glossary of Transcript Symbols with an Introduction. In Conversation Analysis: Studies from the First Generation, ed. G. H. Lerner, 13-23. Philadelphia: John Benjamins.

Keating, Elizabeth, and Maria Egbert. 2004. Conversation as a Cultural Activity. In A Companion to Linguistic Anthropology, ed. Alessandro Duranti, 169-96. New York: Blackwell.

Kendon, Adam. 1980. Gesticulation and Speech: Two aspects of the process of utterance. In The Relationship of Verbal and Nonverbal Communication, ed. Mary Ritchie Key, 207-27. The Hague: Mouton.

1990. Conducting Interaction: Patterns of Behavior in Focused Encounters. Cambridge: Cambridge University Press.

Kidwell, M. 2005. Gaze as Social Control: How very young children differentiate "the look" from a "mere look" by their adult caregivers. Research on Language and Social Interaction 38(4): 417-49.

Kita, Sotaro, ed. 2003. Pointing: Where Language, Culture, and Cognition Meet. Mahwah, NJ: L. Erlbaum Associates.

ed. 2009. Cross-cultural Variation of Speech-accompanying Gesture: A review. Language and Cognitive Processes 24(2): 145-67. doi:10.1080/ 01690960802586188.

Lehtonen, Jaakko, and Kari Sajavaara. 1985. The Silent Finn. In Perspectives on Silence, ed. Deborah Tannen and Muriel Saville-Troike, 193-201. Norwood, NJ: Ablex Pub. Corp.

Lemasson, A., L. Glas, S. Barbu, A. Lacroix, M. Guilloux, K. Remeuf, and H. Koda. 2011. Youngsters Do Not Pay Attention to Conversational 
Rules: Is this so for nonhuman primates? Scientific Reports 1. doi:10.1038/srep00022.

Lerner, Gene H. 2003. Selecting Next Speaker: The context-sensitive operation of a context-free organization. Language in Society 32(02): 177-201. doi:10.1017/S004740450332202X.

Lerner, Gene H., and Tomyo Takagi. 1999. On the Place of Linguistic Resources in the Organization of Talk-in-Interaction: A co-investigation of English and Japanese grammatical practices. Journal of Pragmatics 31(1): 49-75.

Levinson, Stephen C. 2006. The Human Interaction Engine. In Roots of Human Sociality: Culture, Cognition, and Human Interaction, ed. N. J. Enfield and Stephen C. Levinson, 39-69. Oxford: Berg.

2007. Optimizing Person Reference - Perspectives from usage on Rossel Island. In Person Reference in Interaction: Linguistic, Cultural, and Social Perspectives, ed. N.J. Enfield and Tanya Stivers, 29-72. Cambridge: Cambridge University Press.

2013. Action Formation and Ascription. In Handbook of Conversation Analysis, ed. Jack Sidnell and Tanya Stivers, 103-30. Malden, MA: Blackwell Publishers.

Luke, Kang Kwong, and Theodossia-Soula Pavlidou, eds. 2002. Telephone Calls: Unity and Diversity in Conversational Structure Across Languages and Cultures. Philadelphia, PA: J. Benjamins.

Mandelbaum, Jenny. 1990. Beyond Mundane Reason: Conversation Analysis And Context. Research on Language and Social Interaction 24: 333-50. doi:10.1080/08351819009389346.

Márquez-Reiter, Rosina. 2000. Linguistic Politeness in Britain and Uruguay: A Contrastive Study of Requests and Apologies. Amsterdam/Philadelphia: John Benjamins.

McHoul, Alec, Mark Rapley, and Charles Antaki. 2008. You Gotta Light?: On the luxury of context for understanding talk in interaction. Journal of Pragmatics 40(1): 42-54. doi:10.1016/j.pragma.2007.03.006.

McNeill, David. 1992. Hand and Mind. Chicago: University of Chicago Press. Moerman, Michael. 1977. The Preference for Self-Correction in a Tai Conversational Corpus. Language 53(4): 872-82.

1988. Talking Culture: Ethnography and Conversation Analysis. Philadelphia: University of Pennsylvania Press.

1990. Exploring Talk and Interaction. Research on Language and Social Interaction 24: 173-87. doi:10.1080/08351819009389337.

1996. The Field of Analyzing Foreign Language Conversations. Journal of Pragmatics 26(2): 147-58. doi:10.1016/0378-2166(96)00009-4.

Mondada, L. 2007. Multimodal Resources for Turn-taking Pointing and the Emergence of Possible Next Speakers. Discourse Studies 9(2): 194-225.

Nelson, Gaylel, Mahmoud Al-Batal, and Erin Echols. 1996. Arabic and English Compliment Responses: Potential for Pragmatic Failure. Applied Linguistics 17(4): 411-32. doi:10.1093/applin/17.4.411. 
Nettle, Daniel. 1998. Explaining Global Patterns of Language Diversity. Journal of Anthropological Archaeology 17: 354-74.

Nureddeen, Fatima Abdurahman. 2008. Cross Cultural Pragmatics: Apology strategies in Sudanese Arabic. Journal of Pragmatics 40(2): 279-306. doi:10.1016/j.pragma.2007.11.001.

Obeng, S. 1999. Apologies in Akan Discourse. Journal of Pragmatics 31(5): 709-34. doi:10.1016/S0378-2166(98)00089-7.

Ochs, Elinor. 1984. Clarification and Culture. In GURT'84: Meaning, Form, and Use in Context: Linguistic Applications, ed. Deborah Schiffrin. Washington, DC: Georgetown University Press.

Ochs, Elinor, Emanuel A. Schegloff, and Sandra A. Thompson, eds. 1996. Interaction and Grammar. Cambridge: Cambridge University Press.

Pomerantz, Anita. 1990. Mental Concepts In The Analysis of Social Action. Research on Language and Social Interaction 24: 299-310. doi:10.1080/ 08351819009389344.

Reisman, Karl. 1974. Contrapuntal Conversations in an Antiguan Village. In Explorations in the Ethnography of Speaking, ed. Richard Bauman and Joel Sherzer, 110-24. London/New York: Cambridge University Press.

Robinson, Jeffrey D. 2006. Managing Trouble Responsibility and Relationships During Conversational Repair. Communication Monographs 73: 137-61. doi:10.1080/03637750600581206.

Rosaldo, Michelle Z. 1982. The Things We Do with Words: Ilongot Speech Acts and Speech Act Theory in Philosophy. Language in Society 11(2): 203-37.

Rossano, Federico. 2013. Gaze in Social Interaction. In Handbook of Conversation Analysis, ed. Jack Sidnell and Tanya Stivers, 308-29. Malden, MA: Blackwell Publishers.

Rossano, Federico, Penelope Brown, and Stephen C. Levinson. 2009. Gaze, Questioning, and Culture. In Conversation Analysis: Comparative Perspectives, ed. Jack Sidnell, 187-249. Cambridge: Cambridge University Press.

Ruby, Jay. 1980. Franz Boas and Early Camera Study of Behavior. Kinesics Report 3(1): 6-11.

Rue, Yong-Ju. 2008. Request Strategies: A Comparative Study in Mandarin Chinese and Korean. Amsterdam/Philadelphia: John Benjamins.

Sacks, Harvey. 1992. Lectures on Conversation. 2 vols. London: Blackwell.

Sacks, Harvey, Emanuel A. Schegloff, and Gail Jefferson. 1974. A Simplest Systematics for the Organization of Turn-Taking for Conversation. Language 50(4): 696-735.

Sammons, Kay, and Joel Sherzer. 2000. Translating Native Latin American Verbal Art: Ethnopoetics and Ethnography of Speaking. Washington, DC: Smithsonian Institution Press.

Sanders, Robert E. 1999. The Impossibility of a Culturally Contexted Conversation Analysis: On Simultaneous, Distinct Types of Pragmatic Meaning. Research on Language and Social Interaction 32(1/2): 129.

Schegloff, Emanuel A. 1968. Sequencing in Conversational Openings. American Anthropologist 70(6): 1075-95. 
1982. Discourse as Interactional Achievement: Some Uses of "uh huh" and Other Things That Come Between Sentences. In Analyzing Discourse: Text and Talk, ed. Deborah Tannen, 71-93. Washington, DC: Georgetown University Press.

1984. On Some Gestures' Relation to Talk. In Structures of Social Action Studies in Conversation Analysis, ed. J. M. Atkinson and John Heritage, 266-96. Cambridge/New York/Paris: Cambridge University Press / Editions de la Maison des sciences de l'homme.

1992. In Another Context. In Rethinking Context: Language as an Interactive Phenomenon, ed. Alessandro Duranti and Charles Goodwin, 191-227. Cambridge: Cambridge University Press.

1997. Practices and Actions: Boundary cases of other-initiated repair. Discourse Processes 23(3): 499-545. doi:10.1080/01638539709545001. 1998. Body Torque. Social Research 65(3): 535-96.

2000. Overlapping Talk and the Organization of Turn-Taking for Conversation. Language in Society 29(1): 1-63.

2004. On Dispensability. Research on Language and Social Interaction 37(2): 95-149.

2005. On Integrity in Inquiry ... of the Investigated, Not the Investigator. Discourse Studies 7(4-5): 455-80. doi:10.1177/1461445605054402.

2006. Interaction: The Infrastructure for Social Institutions, the Natural Ecological Niche for Language, and the Arena in which Culture is Enacted. In Roots of Human Sociality: Culture, Cognition, and Human Interaction, ed. N.J. Enfield and Stephen C. Levinson, 70-96. Oxford: Berg.

2007. Sequence Organization in Interaction: A Primer in Conversation Analysis. Cambridge: Cambridge University Press.

2013. Ten Operations In Self-Initiated, Same-Turn Repair. In Conversational Repair and Human Understanding, ed. Makoto Hayashi, Geoffrey Raymond, and Jack Sidnell, np. Cambridge: Cambridge University Press.

Schegloff, Emanuel A., Gail Jefferson, and Harvey Sacks. 1977. The Preference for Self-Correction in the Organization of Repair in Conversation. Language 53(2): 361-82.

Schieffelin, Bambi B., and Elinor Ochs, eds. 1986. Language Socialization Across Cultures. Cambridge: Cambridge University Press.

Searle, John R. 1969. Speech Acts: An Essay in the Philosophy of Language. Cambridge: Cambridge University Press.

2006. Social Ontology: Some basic principles. Anthropological Theory 6(1): 12-29. doi:10.1177/1463499606061731.

Shariati, Mohammad, and Fariba Chamani. 2010. Apology Strategies in Persian. Journal of Pragmatics 42(6): 1689-99. doi:10.1016/j.pragma.2009. 10.007 .

Sherzer, Joel. 1973. Verbal and Nonverbal Deixis: The Pointed Lip Gesture Among the San Blas Cuna. Language in Society 2(01): 117-31. doi:10.1017/S0047404500000087. 
1983. Kuna Ways of Speaking: An Ethnographic Perspective. Austin: University of Texas Press.

Sidnell, Jack. 2001. Conversational Turn-taking in a Caribbean English Creole. Journal of Pragmatics 33(8): 1263-90. doi:16/S0378-2166(00)00062-X.

2005. Talk and Practical Epistemology: The Social Life of Knowledge in a Caribbean Community. Amsterdam/Philadelphia: Johns Benjamins.

2006. Conversational Analytic Approaches to Culture. In Encyclopedia of Language and Linguistics, ed. Keith Brown, 169-72. Oxford: Elsevier. www.sciencedirect.com/science/article/B7T84-4M3C3K0-2MX/2/b93e 2e9491643ddb591c655f9a277c60.

2007. Comparative Studies in Conversation Analysis. Annual Review of Anthropology 36(1): 229-44. doi:10.1146/annurev.anthro.36.081406. 094313.

ed. 2009. Conversation Analysis: Comparative Perspectives. Cambridge: Cambridge University Press.

2010. Conversation Analysis: An Introduction. Chichester, UK: WileyBlackwell.

Sidnell, Jack, and N. J. Enfield. 2012. Language Diversity and Social Action. Current Anthropology 53(3): 302-33. doi:10.1086/665697.

Smith, Jonathan Z. 1992. To Take Place: Toward Theory in Ritual. Chicago: University of Chicago Press.

Stivers, Tanya, N. J. Enfield, Penelope Brown, C. Englert, Makoto Hayashi, Trine Heinemann, Gertie Hoymann, et al. 2009. Universals and Cultural Variation in Turn-taking in Conversation. Proceedings of the National Academy of Sciences 106(26): 10587-92. doi:10.1073/ pnas.0903616106.

Stivers, Tanya, and Jack Sidnell. 2005. Introduction: Multimodal interaction. Semiotica 156(1/4): 1-20.

Stoller, Paul. 1989. Fusion of the Worlds: An Ethnography of Possession Among the Songhay of Niger. University of Chicago Press, July 10.

Streeck, Jürgen. 1990. Tao/Saó: Talking Culture With Rousseau. Research on Language and Social Interaction 24: 241-61. doi:10.1080/08351819 009389341.

1993. Gesture as Communication I: Its coordination with gaze and speech. Communication Monographs 60(4): 275-99.

Sudnow, David N., ed. 1972. Studies in Social Interaction. New York: MacMillan/The Free Press.

Tang, Chen-Hsin, and Grace Qiao Zhang. 2009. A Contrastive Study of Compliment Responses among Australian English and Mandarin Chinese speakers. Journal of Pragmatics 41(2): 325-45. doi:10.1016/j. pragma.2008.05.019.

Tedlock, Dennis. 1983. The Spoken Word and the Work of Interpretation. Philadelphia: University of Pennsylvania Press.

Urban, Greg. 1986. Ceremonial Dialogues in South America. American Anthropologist 88(2): 371-86. doi:10.1525/aa.1986.88.2.02a00050. 
Whitehead, Kevin A. 2011. Some Uses of Head Nods in Third Position in Talk-in-Interaction. Gesture 11(2): 103-22. doi:10.1075/gest.11.2.01whi.

Ylänne-McEwen, Virpi. 1993. Complimenting Behaviour: A cross-cultural investigation. Journal of Multilingual and Multicultural Development 14(6): 499-508. doi:10.1080/01434632.1993.9994551.

Yoshida, Shigeto, and Kazuo Okanoya. 2005. Evolution of Turn-Taking: A Bio-Cognitive Perspective. Cognitive Studies 12(3): 153-65.

Zimmerman, Don H. 1999. Horizontal and Vertical Comparative Research in Language and Social Interaction. Research on Language and Social Interaction 32(1-2): 195-203. doi:10.1080/08351813.1999.9683623. 